secondary care work collaboratively. We may need a unified bed management team in every primary care trust which can allocate the patient after initial assessment to an acute hospital, a community hospital or to intermediate care. This requires training and commitments from all staff. The whole health and social care system should plan together how to meet the demand of the increasing elderly population. I should also emphasise the importance of multidisciplinary teams in each trust for effective discharge planning.

\section{IBRAHIM MORGAN}

Consultant physician/geriatrician University Hospital of North Staffordshire

\section{'With a pinch of salt' revisited}

Editor - I read with interest but some concern the recent lesson of the month by Gangopadhyay et al (Clin Med February 2010 pp 86-7). The lesson highlights a case of severe hyponatraemia which the authors attribute to excessive sweating, poor fluid consumption and low salt intake in a hot environment. There is little evidence to suggest that low salt intake would contribute to this event and the authors have not explored alternative likely explanations. During evolution mankind has survived with very little salt in the diet. Even in modern times, this evidence is detectable in the Yanomano and Xingu Indians living in the humid and hot environment of the Amazon jungle. ${ }^{1}$ Their average salt intake, when measured by 24 hour urine collections, varies between 1 and $10 \mathrm{mmol} /$ day. These levels of salt intake, however, are almost unseen in the western world due to the high salt intake we are exposed to, even when adhering to a low salt diet. Under conditions of exercise in a hot environment, a low salt intake does not impair the ability to exercise, and it does not cause changes in plasma sodium, potassium, osmolality or sweat rate, although the salt content of sweat is reduced on a low salt diet. $^{2}$ They misquote the evidence in athletes and the military where the high morbidity from hyponatraemia is due to overhydration (ie too much water) rather that a low salt intake. The case presented here is clearly a case of diuretic abuse, surreptitious vomiting or laxative abuse, as we described in the past in a different scenario. ${ }^{3}$ While hyponatraemia may possibly have been caused by water intoxication, it would not have caused plasma potassium to fall so low, or the renin-angiotensin system to be so stimulated. The authors do not seem to have considered screening for diuretics. Diuretic abuse would explain hyponatraemia, alkalotic hypokalaemia, and activation of the renin-angiotensin-aldosterone system as described here. A moderate reduction in salt intake (up to $3 \mathrm{~g}$ per day) does not raise cause for concern and should be recommended to everyone to prevent cardiovascular disease and other common conditions like kidney stones and osteoporosis. ${ }^{4}$

FRANCESCO P CAPPUCCIO Professor of cardiovascular medicine and epidemiology University of Warwick, Warwick Medical School

\section{References}

1 Mancilha Carvalho JJ, Baruzzi RG, Howard $\mathrm{PF}$ et al. Blood pressure in four remote populations in the INTERSALT Study. Hypertension 1989;14:238-46.

2 Hargreaves M, Morgan TO, Snow R, Guerin M. Exercise tolerance in the heat on low and normal salt intakes. Clin Sci 1989;76:553-7.

3 Missouris CG, Cappuccio FP, Markandu ND, MacGregor GA. Diuretics and oedema: how to avoid rebound sodium retention. Lancet 1992;339:1546.

4 MacGregor GA, Cappuccio FP. The kidney and essential hypertension: a link to osteoporosis. J Hypertens 1993;11:781-5.

\section{Serum sodium disorders: safe management}

Editor - I suspect that Wakil and Atkin were set an impossible task, in reviewing the aetiology, assessment and acute mangement of hyponatraemia and hypernatraemia in three pages (Clin Med February pp 79-82)! The 2007 American guidelines on hyponatraemia alone run to 21 pages, including 120 references. ${ }^{1}$ However, the authors of the CME acute medicine review covered this complex topic in a readily accessible manner, for which they should be commended. However, I fear that a number of important and clinically relevant points were not highlighted due to space limitations. Firstly, the contribution of excessive water intake to hyponatraemia should be stressed. Although classically presented as a psychiatric condition of psychogenic polydipsia, water intoxication is an important differential diagnosis for hyponatraemia. It can also cause a diagnostic challenge and contributes to many cases of hyponatraemia. This was evident in the lesson of the month, published in the same edition of Clinical Medicine, where a young man presented with hypovolaemic hyponatraemia. ${ }^{2}$ Secondly, it should be stressed that in older patients with low serum sodium levels, there are often multiple contributing factors. Diuretic therapy may promote hypovolaemia; co-morbidities such as chronic kidney disease or heart failure cause a tendency to hypervolaemia. At the same time, underlying diseases or other medicines such as tricyclic or selective serotonin-reuptake inhibitor antidepressants may cause inappropriate antidiuretic hormone $(\mathrm{ADH})$ secretion. However, the authors' advice that, where there is doubt, isotonic saline should be given is probably valid; but the response to this therapy may be unpredictable. Finally, I worry that the review lacked sufficient detail on pharmacological therapy, advocating the use of new aquaretic drugs but without mention of demeclocycline, which is still commonly prescribed. However, I would strongly counsel against the use of such agents in the acute setting and only where there is a clear diagnosis (with an underlying cause for) inappropriate $\mathrm{ADH}$ secretion.

TERRY J ASPRAY

Consultant physician Sunderland Royal Hospital

\section{References}

1 Verbalis JG, Goldsmith SR, Greenberg A, Schrier RW, Sterns RH. Hyponatremia treatment guidelines 2007: expert panel recommendations. Am J Med 2007 Nov;120 (11 Suppl 1):S1-21.

2 Gangopadhyay KK, Gupta R, Baskar V, Gautem N, Toogood AA. With a pinch of salt. Clin Med 2010;10:86-7.

\section{In response}

We thank Aspray for the comment on our article. In answering the first point we 